\title{
Kinetics and mechanism of protection of thymine from sulphate radical anion under anoxic conditions
}

\author{
M SUDHA SWARAGA and M ADINARAYANA* \\ Department of Chemistry, Osmania University, Hyderabad 500 007, India \\ e-mail: mundra_adinarayana@hotmail.com
}

MS received 2 March 2002; revised 20 December 2002

\begin{abstract}
The rates of photooxidation of thymine in presence of peroxydisulphate (PDS) have been determined by measuring the absorbance of thymine at $264 \mathrm{~nm}$ spectrophotometrically. The rates and the quantum yields $(\phi)$ of oxidation of thymine by sulphate radical anion have been determined in the presence of different concentrations of caffeic acid. Increase in [caffeic acid] is found to decrease the rate of oxidation of thymine suggesting that caffeic acid acts as an efficient scavenger of $\mathrm{SO}_{4}^{--}$and protects thymine from it. Sulphate radical anion competes for thymine as well as for caffeic acid. The rate constant of sulphate radical anion with caffeic acid has been calculated to be $1.24 \times 10^{10} \mathrm{dm}^{3} \mathrm{~mol}^{-1} \mathrm{~s}^{-1}$. The quantum yields of photooxidation of thymine have been calculated from the rates of oxidation of thymine and the light intensity absorbed by PDS at $254 \mathrm{~nm}$, the wavelength at which PDS is activated to sulphate radical anion. From the results of experimentally determined quantum yields $\left(\phi_{\text {exptl }}\right)$ and the quantum yields calculated $\left(\phi_{\mathrm{cl}}\right)$ assuming caffeic acid acting only as a scavenger of $\mathrm{SO}_{4}^{--}$radicals show that $\phi_{\text {exptl }}$ values are lower than $\phi_{\mathrm{cl}}$ values. The $\phi^{\prime}$ values, which are experimentally found quantum yield values at each caffeic acid concentration and corrected for $\mathrm{SO}_{4}^{\circ-}$ scavenging by caffeic acid, are also found to be greater than $\phi_{\text {exptl }}$ values. These observations suggest that the thymine radicals are repaired by caffeic acid in addition to scavenging of sulphate radical anions.
\end{abstract}

Keywords. Oxidation of caffeic acid; repair of thymine by caffeic acid; oxidations by sulphate radical anion.

\section{Introduction}

It is generally accepted that the lethal effects of ionizing radiation on cellular systems involve radical induced chemical changes in essential biomolecules, particularly deoxyribonucleic acid (DNA). ${ }^{1}$ It is also known that hydroxycinnamic acids are natural antioxidants and their antioxidant and antifungal activity is mainly due to their ability to scavenge several oxidizing free radicals. In recent times focus is on the protective action of naturally occurring antioxidants and in this connection studies involving caffeic acid assume importance due to the wide spread occurrence of this antioxidant in nature. When DNA is subjected to ionizing radiation many different changes can occur in DNA, ${ }^{2}$ ranging from various kinds of base modifications to single and double strand breaks. Even though sugar radicals are actually responsible for strand break formation in DNA, experimental results clearly indicate that base radicals can contribute significantly via

*For correspondence 
transfer of radical sites from base moiety to sugar moiety. Strand breaks are considered to be a very serious kind of damage to DNA.,4

Ionizing radiation causes damage to DNA by direct effect and indirect effect. The former is caused by the absorption of the ionizing radiation by the DNA molecule itself, the later by water radicals generated upon absorption of the ionizing radiation by water. It is very difficult to distinguish experimentally between these two modes of damage formation in DNA. On the absorption of ionizing radiation, DNA molecule undergoes a chemical change giving radical cation which on spontaneous deprotonation gives DNA radical, the chemistry of which is similar to DNA radicals produced by $\mathrm{OH}$ radicals. In order to mimic and understand the mechanism of direct effect of ionizing radiation on DNA, Bansal and Fessenden ${ }^{5}$ have used sulphate radical anion $\left(\mathrm{SO}_{4}^{\bullet-}\right)$ a strong electrophilic radical to create radical cation in uracil and substituted uracils. Ravi Kumar and Adinarayana ${ }^{6}$ reported that 5 -yl radicals obtained from photooxidation of thymine by peroxydiphosphate (PDP) have been repaired to a greater extent at about $50 \mu \mathrm{m}$ of dithiothreitol (DTT). In this paper we report the results on the protection of thymine from sulphate radical anion by caffeic acid. From the competition kinetic studies of $\mathrm{SO}_{4}^{\bullet-}$ with thymine and caffeic acid the rate constant of $\mathrm{SO}_{4}^{--}$reaction with caffeic acid has been evaluated. Further an attempt has also been made to evaluate the extent of repair of thymine radicals by caffeic acid.

\section{Experimental}

Thymine and peroxydisulphate (PDS) were purchased from E. Merck, while caffeic acid was from sigma. All solutions were prepared using double distilled water. Stock solutions of thymine and caffeic acid were always freshly prepared and were deaerated by bubbling nitrogen. The solutions of potassium salt of peroxydisulphate was prepared using double distilled water and standardised using cerimetry using ferroin indicator. Peroxydisulphate solution was added to a measured excess of ferrous ammonium sulphate, and back titrated with a standard ceric ammonium sulphate solution as reported by Kapoor et al. ${ }^{7}$ At room temperature this reaction is rapid enough for analytical purposes and equivalency of ferrous ion to peroxydisulphate is 2 to 1 . Required amounts of caffeic acid were then injected as aqueous solution into the mixture of thymine and PDS solutions present in a specially designed $1-\mathrm{cm}$ path length quartz cuvette which is suitable for both irradiations in the quantum yield reactor as well as for absorbance measurements. The absorbance measurements were made at $264 \mathrm{~nm}$, which is the $\lambda_{\max }$ of thymine on a HITACHI UV-Vis spectrophotometer (model 3410). Irradiations, were performed at room temperature $\left(25^{\circ} \mathrm{C}\right)$ with high-pressure mercury lamp using Quantum yield reactor model QYR-20. The irradiations were interrupted at definite intervals of time and the absorbance was noted from which the rate of reaction and the quantum yields of oxidation are calculated. The light intensity at $254 \mathrm{~nm}$ was measured by peroxydisulphate chemical actinometry. ${ }^{8}$ The light intensity absorbed by PDS was calculated using the following equation.

$$
I_{\mathrm{PDS}}=\frac{\varepsilon_{\mathrm{PDS}}[\mathrm{PDS}]}{\varepsilon_{\mathrm{PDS}}[\mathrm{PDS}]+\varepsilon_{\text {thymine }}[\text { thymine }]} \times I_{t},
$$

$I_{\mathrm{PDS}}=$ intensity of light absorbed by peroxydisulphate in a reaction mixture; $I_{t}=$ total intensity of light measured from peroxydisulphate actinometry; $\varepsilon_{\mathrm{PDS}}=$ molar absorption 
coefficient of peroxydisulphate at $254 \mathrm{~nm},\left(24.1 \mathrm{dm}^{3} \mathrm{~mol}^{-1} \mathrm{~cm}^{-1}\right) ; \varepsilon_{\text {pyrimidine }}=$ molar absorption coefficient of thymine at $254 \mathrm{~nm}\left(6250 \mathrm{dm}^{3} \mathrm{~mol}^{-1} \mathrm{~cm}^{-1}\right)$.

\section{Results and discussion}

$\mathrm{N}_{2}$-saturated aqueous solutions of the reaction mixture containing thymine $(0.5 \times$ $\left.10^{-4} \mathrm{~mol} \mathrm{dm}^{-3}\right)$, PDS $\left(4.0 \times 10^{-4} \mathrm{~mol} \mathrm{dm}^{-3}\right)$ and caffeic acid were irradiated and the absorbance at $264 \mathrm{~nm}$ ( $\lambda_{\max }$ of thymine) with time were noted from which the rates of oxidation of thymine were calculated from the plots of absorbance versus time using a microcal origin computer program on personal computer (table 1, figure 1). $\mathrm{N}_{2}$-saturated aqueous solution of the reaction mixture containing caffeic acid and PDS were irradiated and the absorbance at $310 \mathrm{~nm}$ ( $\lambda_{\max }$ of caffeic acid) with time were noted from which the rates of oxidation of caffeic acid were calculated from the plots of absorbance versus time using microcal origin computer program. The initial rates of oxidation of caffeic acid by

Table 1. Photooxidation of thymine in presence of peroxydisulphate at various [caffeic acid] in aqueous anoxic solutions.

$[$ Thymine $]=5.00 \times 10^{-5} \mathrm{~mol} \mathrm{dm}^{-3} ;[\mathrm{PDS}]=4.00 \times 10^{-4} \mathrm{~mol} \mathrm{dm}^{-3}$, temp. $=298 \mathrm{~K}$

\begin{tabular}{|c|c|c|c|c|c|c|}
\hline \multirow[b]{2}{*}{ Irradiation time $(\mathrm{min})$} & \multicolumn{6}{|c|}{ Absorbance at $264 \mathrm{~nm}$ in presence of caffeic acid concentrations* } \\
\hline & 0.00 & $1 \cdot 00$ & $5 \cdot 00$ & $10 \cdot 00$ & $20 \cdot 00$ & $50 \cdot 00$ \\
\hline 0 & $0 \cdot 384$ & $0 \cdot 382$ & $0 \cdot 382$ & $0 \cdot 384$ & $0 \cdot 384$ & $0 \cdot 384$ \\
\hline 3 & $0 \cdot 332$ & $0 \cdot 335$ & $0 \cdot 371$ & $0 \cdot 370$ & $0 \cdot 373$ & 0.378 \\
\hline 6 & $0 \cdot 270$ & $0 \cdot 275$ & $0 \cdot 342$ & $0 \cdot 364$ & $0 \cdot 366$ & $0 \cdot 376$ \\
\hline 9 & $0 \cdot 202$ & $0 \cdot 221$ & $0 \cdot 291$ & $0 \cdot 360$ & $0 \cdot 360$ & 0.381 \\
\hline 12 & $0 \cdot 137$ & $0 \cdot 150$ & 0.234 & $0 \cdot 355$ & $0 \cdot 360$ & 0.369 \\
\hline 15 & 0.080 & 0.090 & $0 \cdot 168$ & $0 \cdot 350$ & $0 \cdot 352$ & 0.368 \\
\hline
\end{tabular}

*Concentration of caffeic acid in $\mu \mathrm{M}$

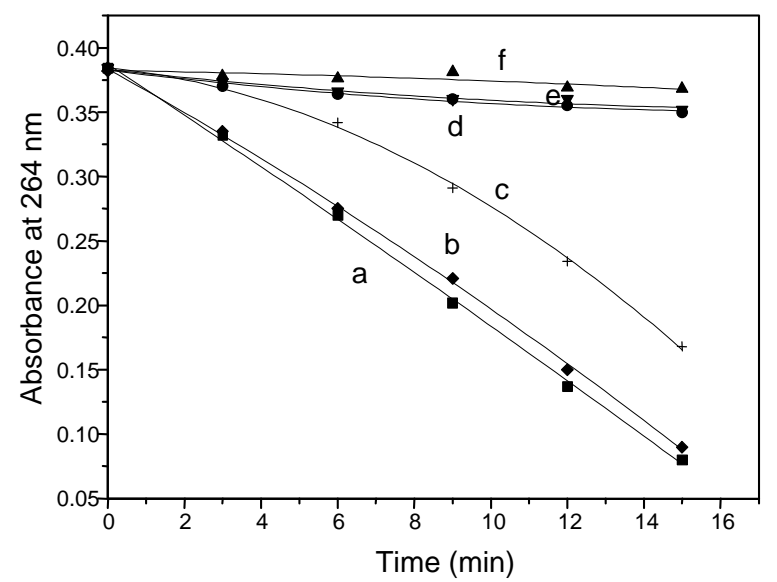

Figure 1. Effect of caffeic acid on the photooxidation of thymine by PDS [thymine] $=5 \times 10^{-5} \mathrm{~mol} \mathrm{dm}^{-3} ; \quad$ [caffeic acid] $=0.00 \quad$ (a), $1 \times 10^{-6} \mathrm{~mol} \mathrm{dm}^{-3}$ (b), $5.00 \times 10^{-6} \mathrm{~mol} \mathrm{dm}^{-3}$ (c), $1.00 \times 10^{-5} \mathrm{~mol} \mathrm{dm}^{-3}$ (d), $2 \times 10^{-5} \mathrm{~mol} \mathrm{dm}^{-3}$ (e) and $5 \times$ $10^{-5} \mathrm{~mol} \mathrm{dm}^{-3}(\mathrm{f})$. 
Table 2. Rates of photooxidation of caffeic acid in presence of peroxydisulphate (PDS) at various [caffeic acid] in aqueous anoxic solution.

$[\mathrm{PDS}]=4.00 \times 10^{-4} \mathrm{~mol} \mathrm{dm}^{-3} ;$ temp. $=298 \mathrm{~K}$

\begin{tabular}{lllll}
\hline $10^{5} \times[$ Caffeic acid $]\left(\mathrm{mol} \mathrm{dm}^{-3}\right)$ & $0 \cdot 1$ & $0 \cdot 5$ & $2 \cdot 0$ & $5 \cdot 0$ \\
$10^{8} \times$ Rate $\left(\mathrm{mol} \mathrm{dm} \mathrm{s}^{-1}\right)$ & 0.005 & 0.003 & $2 \cdot 48$ & $3 \cdot 00$ \\
\hline
\end{tabular}

Table 3. Effect of [caffeic acid] on the quantum yields of photooxidation of thymine in presence of peroxydisulphate (PDS) under anoxic conditions.

Light intensity $=1.03 \times 10^{15}$ quanta s $^{-1}$; $[\mathrm{PDS}]=4.00 \times 10^{-4} \mathrm{~mol} \mathrm{dm}^{-3}$; [thymine] $=$ $5 \times 10^{-5} \mathrm{~mol} \mathrm{dm}^{-3} ; \mathrm{pH} \sim 7 \cdot 5$, temp. $=298 \mathrm{~K}$

\begin{tabular}{|c|c|c|c|c|c|c|}
\hline $\begin{array}{l}10^{5} \times[\text { Caffeic acid }] \\
\left(\mathrm{mol} \mathrm{dm}^{-3}\right)\end{array}$ & $\begin{array}{c}10^{8} \times \text { rate } \\
\left(\mathrm{mol} \mathrm{dm} \mathrm{dm}^{-3} \mathrm{~s}^{-1}\right)\end{array}$ & $\phi_{\text {exptl }}$ & $\phi_{\mathrm{cl}}$ & $\phi^{\prime}$ & $\%$ Scavenging & \% Repair \\
\hline $0 \cdot 0$ & $4 \cdot 250$ & $2 \cdot 513$ & $2 \cdot 513$ & $2 \cdot 513$ & 0.00 & $0 \cdot 00$ \\
\hline $0 \cdot 1$ & 2.600 & 1.530 & 2.000 & 1.912 & 19.88 & 23.80 \\
\hline 0.5 & $1 \cdot 170$ & 0.690 & $1 \cdot 120$ & 1.540 & $55 \cdot 40$ & 38.43 \\
\hline 1.0 & 0.600 & $0 \cdot 352$ & 0.721 & $1 \cdot 226$ & $71 \cdot 30$ & $51 \cdot 20$ \\
\hline $2 \cdot 0$ & $0 \cdot 264$ & $0 \cdot 156$ & 0.419 & 0.934 & $83 \cdot 30$ & $62 \cdot 86$ \\
\hline $3 \cdot 0$ & 0.044 & 0.026 & $0 \cdot 187$ & $0 \cdot 348$ & $92 \cdot 50$ & $86 \cdot 15$ \\
\hline
\end{tabular}

sulphate radical anion at various (caffeic acid) concentrations are given in table 2. The initial rates of oxidation of thymine by sulphate radical anion have been found to decrease with increase in (caffeic acid) concentration (table 3, figure 1). The quantum yields of oxidation of thymine were calculated from the rates of oxidation of thymine by sulphate radical anion and the light intensity absorbed by PDS at $254 \mathrm{~nm}$, the wavelength at which PDS is activated to sulphate radical anions. The quantum yields of oxidation of thymine $\left(\phi_{\text {exptl }}\right)$ at different (caffeic acid) concentrations are presented in table 3 . The $\phi_{\text {exptl }}$ values were found to decrease with increasing concentration of caffeic acid. Since in this system there is competition between thymine and caffeic acid for $\mathrm{SO}_{4}^{--}$, the relative amounts of $\mathrm{SO}_{4}^{--}$reacting with thymine decreases with increasing concentration of [caffeic acid]. It is interesting to observe that the point of saturation is reached as far as the repair by caffeic acid is concerned. This is evident from the absorbance values in table 1 at $\geq 10 \mu \mathrm{M}$ concentration of caffeic acid. The rate constant of the reaction of the sulphate radical anion with thymine has been reported to be $1 \times 10^{9} \mathrm{dm}^{3} \mathrm{~mol}^{-1} \mathrm{~s}^{-1}$. The rate constant for the reaction of sulphate radical anion with caffeic acid has been calculated by the thymine competition method, which is very similar to the one chosen by Akhalaq et $a l^{10}$ to determine the rate constant for the reaction of $\mathrm{OH}$ radicals with polyhydric alcohols in competition with KSCN. In the photolysis experiment, oxygenfree $\mathrm{N}_{2}$-saturated solutions containing thymine and varying amounts of caffeic acid were irradiated for six minutes and the decrease of absorbance of thymine was measured. The decrease of absorbance of thymine reflects the number of sulphate radical anions that have reacted with thymine. From the rate constant of reaction of thymine with $\mathrm{SO}_{4}^{--}$ $\left(k_{\text {thymine }}=1 \times 10^{9} \mathrm{dm}^{3} \mathrm{~mol}^{-1} \mathrm{~s}^{-1}\right)$ the rate constant of $\mathrm{SO}_{4}^{--}$reaction with caffeic acid $\left(k_{\text {caffeic acid }}\right)$ can be calculated using (2).

$$
\frac{[\text { absorbance of thymine }]_{0}}{[\text { absorbance of thymine }]_{\text {caffeic acid }}}=1+\frac{k_{\text {caffeic acid }}[\text { caffeic acid }]}{k_{\text {thymine }}[\text { thymine }]},
$$


where [absorbance of thymine $]_{0}$ and \{absorbance of thymine $]_{\text {caffeic acid }}$ indicate the decrease in the absorbance of thymine in the absence and presence of caffeic acid respectively, in the same interval of time. Experiments of this kind can be carried out with great accuracy. The rate constant for the reaction of sulphate radical anion with caffeic acid has been calculated with five different concentrations of caffeic acid, and the average value obtained is $1.24 \times 10^{10} \mathrm{dm}^{3} \mathrm{~mol}^{-1} \mathrm{~s}^{-1}$.

The probability of $\mathrm{SO}_{4}^{--}$radicals reacting with thymine $\left\{p\left(\mathrm{SO}_{4}^{--}+\right.\right.$thymine $\left.)\right\}$is calculated using the following equation.

$$
p\left(\mathrm{SO}_{4}^{\bullet-}+\text { thymine }\right)=\frac{[\text { thymine }] k_{\text {thymine }}}{[\text { thymine }]+k_{\text {thymine }}+[\text { caffeic acid }] k_{\text {caffeic acid }}},
$$

$k_{\text {thymine }}$ and $k_{\text {caffeic acid }}$ are the rate constants of $\mathrm{SO}_{4}^{--}$with thymine and caffeic acid respectively. If caffeic acid scavenges only $\mathrm{SO}_{4}^{\bullet-}$ radicals and does not give rise to any other reaction (e.g. repair) the $\phi_{\text {exptl }}$ at each [caffeic acid] should be given by

$$
\phi_{\mathrm{cl}}=\phi_{\mathrm{exptl}}^{0} \times p,
$$

where $\phi_{\text {exptl }}^{0}$ is the quantum yield of oxidation of thymine in the absence of caffeic acid, and $p$ is the probability given by (3). The $\phi_{\mathrm{cl}}$ values at different caffeic acid concentrations are presented in table 3 . It is clear from the data in table 3 that the calculated quantum yield values $\left(\phi_{\mathrm{cl}}\right)$ are larger than the experimentally measured quantum yield values $\left(\phi_{\text {exptl }}\right)$. The difference in $\phi_{\mathrm{cl}}$ and $\phi_{\text {exptl }}$ values is proposed to be due to the prevention of chromophore loss by $\mathrm{H}$ atom donation to thymine radicals by caffeic acid. From the rate constant of sulphate radical anion with caffeic acid, the fraction of $\mathrm{SO}_{4}^{--}$radicals scavenged by caffeic acid (percentage scavenged $=(1-p) \times 100$ ) at different (caffeic acid) were calculated (table. 3). These values were a measure of protection of thymine due to scavenging of $\mathrm{SO}_{4}^{\bullet-}$ radicals by caffeic acid. Table 3 also contains the $\phi^{\prime}$ values, which are experimentally found $\phi$ values at each caffeic acid concentration corrected for sulphate radical anion $\left(\mathrm{SO}_{4}^{\bullet-}\right)$ scavenging by caffeic acid.

$$
\phi^{\prime}=\phi_{\text {exptl }} / p
$$

The $\phi^{\prime}$ values represent the experimentally found $\phi$ values if no scavenging of $\mathrm{SO}_{4}^{--}$ radicals by caffeic acid occurs and hence, in the absence of repair of thymine radicals by caffeic acid, $\phi^{\prime}$ values should all be equal to $\phi_{\text {exptl }}^{0}$. The observed decrease in the $\phi^{\prime}$ with increasing caffeic acid concentration (table 3) indicates the occurrence of repair of thymine radicals. The fraction of oxidation of thymine inhibited by repair of thymine radicals is given by

$$
\text { Percentage repair }=\left[\left(\phi_{\text {exptl }}^{0}-\phi^{\prime}\right) / \phi_{\text {exptl }}^{0}\right] \times 100
$$

The data on percentage repair are presented in table 3 .

The experimentally determined quantum yield values $\left(\phi_{\text {exptl }}\right)$ are lower than the quantum yield values $\left(\phi_{\mathrm{cl}}\right)$ calculated using (4) under the assumption that caffeic acid acts only as a $\mathrm{SO}_{4}^{\bullet-}$ radical scavenger. This shows that caffeic acid is acting not only as an 


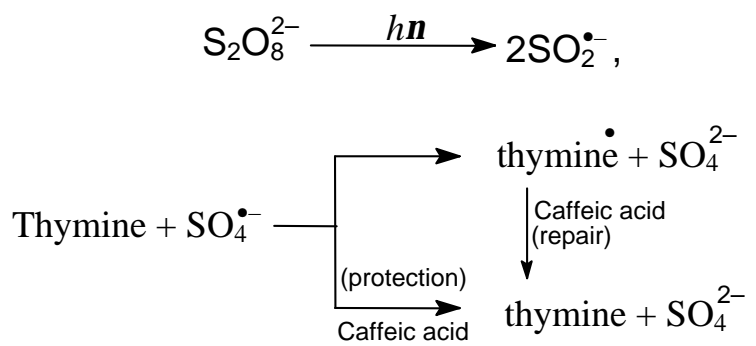

Scheme 1.

efficient scavenger of $\mathrm{SO}_{4}^{--}$but also acts as an agent for the repair of thymine radicals. It is therefore obvious that caffeic acid is reacting not only with $\mathrm{SO}_{4}^{--}$radicals but also with thymine radicals. The repair reaction of caffeic acid is explained in terms of the $\mathrm{H}$ donation. It has been reported that the product formed in the photooxidation of thymine by PDS is via $5 y 1$ radicals because of steric influence of methyl group present at C5 position. From the results obtained in the present work (table 3) indicate that the 5yl radicals are efficiently repaired by caffeic acid to the extent of $\sim 86 \%$ at about $50 \mu \mathrm{M}$ of [caffeic acid]. The reactions of protection of thymine and repair of thymine radicals are given in scheme 1 .

\section{Conclusions}

Photochemical oxidation studies of thymine in presence of various [caffeic acid] have been carried out under different experimental conditions. From competition kinetic studies of thymine and caffeic acid for $\mathrm{SO}_{4}^{\bullet-}$ the rate constant of reaction of $\mathrm{SO}_{4}^{\bullet-}$ with caffeic acid has been calculated. From the experimental quantum yield values $\left(\phi_{\text {exptl }}\right)$ and the calculated quantum yield values assuming caffeic acid acting as a scavenger $\left(\phi_{\mathrm{cl}}\right)$, the percentage repair of thymine radicals have been calculated.

\section{Acknowledgements}

The authors thank Prof P Jayaprakash Rao for helpful discussions. MSS is thankful to the Council of Scientific and Industrial Research, New Delhi, for a fellowship.

\section{References}

1. von Sonntag C 1987 The chemical basis of radiation biology (London: Taylor \& Francis)

2. Hutchinson F 1985 Progr. Nucleic Acid Res. Mol. Biol. 32115

3. Adinarayana M, Bothe E and Shulte-Frohlinde D 1988 Int. J. Radiat. Biol. 54723

4. Lemaire D G E, Bothe E and Sculte-Frohlinde D 1984 Int. J. Radiat. Biol. 45351

5. Bansal K M and Fessenden R W 1978 Radiat. Res. 75497

6. Ravi Kumar M and Adinarayana M 2001 Int. J. Chem. Kinet. 33271

7. Kapoor S, Sharma P D and Gupta Y K 1975 Talanta 22765

8. Ravi Kumar M, Thirupathi Rao M and Adinarayana M 1998 Indian J. Chem. A37 346

9. Deeble D J, Schuchmann M N, Steenken S and von Sonntag C 1990 J Phys. Chem. 948186

10. Akhalaq M S, Al-Baghdad S and von Sonntag C 1987 Carbohydrate Res. 16471 